\title{
OEDIPE: A Personalized Dosimetric Tool Associating Voxel-Based Models with MCNPX
}

\author{
Sophie Chiavassa, ${ }^{1}$ Manuel Bardiès, ${ }^{3}$ Françoise Guiraud-Vitaux, ${ }^{2}$ Damien Bruel, ${ }^{2}$ \\ Jean-Rene Jourdain, ${ }^{1}$ Didier Franck, ${ }^{1}$ and Isabelle Aubineau-Lanièce ${ }^{1}$ \\ ${ }^{1}$ Institute for Radiological Protection and Nuclear Safety-IRSN/DRPH/SDI, Fontenay-aux-Roses, \\ France \\ ${ }^{2}$ Biophysics Laboratory of Medicine Faculty of X. Bichat, Paris, France \\ ${ }^{3}$ French Institute of Health and Medial Research-INSERM U601, Nantes, France
}

\begin{abstract}
Aim: A new tool, named OEDIPE (a French acronym that stands for "Tool for Personalized Internal Dose Assessment") was developed to carry out personalized internal dosimetry calculations for nuclear medicine (for both therapeutic and diagnostic procedures) and for radiation safety (in the case of internal contamination). It was developed under the PV-Wave ${ }^{\circledR}$ visual data analysis system by the Institute of Radioprotection and Nuclear Safety (IRSN) in collaboration with the French Institute of Health and Medical Research (INSERM). This software creates anthropomorphic voxel-based phantoms from computed tomography (CT) and magnetic resonance imaging (MRI) patient images through the use of a friendly graphical user interface (GUI). Several tools have been built-in to allow for image segmentation. Source data, including VOI localization and cumulated activities, are assessed by single photon emission computed tomography (SPECT) images, and the source may be specified in any number of organs either as a point source or a homogeneously distributed source. It is also possible to choose the dosimetric parameters required for the study (mean organ dose or a dose distribution). Phantom, source, and dosimetric parameters are automatically written into a file. That file is then processed by the Monte Carlo code MCNPX (LANL) to perform the actual dose calculation. Results: OEDIPE can compute either the absorbed dose in each organ (in a few minutes), or the absorbed dose in each voxel of the phantom (i.e. the spatial dose distribution at a tissue level) in a few hours or more. OEDIPE automatically reads the MCNPX output file and processes results to give a list of absorbed doses in each organ or a plot of isodose curves superimposed onto the phantom. Because of the long calculation times required to compute an absorbed dose within an entire whole-body phantom at a spatial resolution of a few millimeters, modifications were made to reduce computational times to reasonable values. To illustrate this tool, results of a dosimetric study of technetium-99m labeling of a bone-scanning agent are presented. Conclusion: OEDIPE is a tool that can be used for patient-specific dosimetry-for example, in targeted radiotherapy-by taking into account the individual patient anatomy, including tumors.
\end{abstract}

Key words: Monte Carlo, voxel-based models, specific dosimetry, targeted radiotherapy

\section{INTRODUCTION}

Address reprint requests to: Manuel Bardiès; French Institute of Health and Medical Research; INSERM U601, 9, quai Moncousu, 44093 Nantes Cedex, France; Tel.: +02-40-41-28-21; Fax: +02-40-35-66-97

E-mail c/o: Sophie.Chiavassa@nantes.inserm.fr
Medical Internal Radiation Dose (MIRD) ${ }^{1}$-based $S$ factors are usually applied for dosimetry calculations for diagnostic imaging. In that context, the use of mathematical models to describe pa- 
tient anatomy is commonly accepted. The development of more accurate methods to perform three-dimensional (3D) patient-specific dosimetry is necessary to optimize internal radiotherapy-for example, in the context of radioimmunotherapy. ${ }^{2}$ Patient computed tomography (CT) images provide specific anatomical information that can be used to create personalized voxel-based models. 3D personalized voxel dosimetry is, therefore, possible using a Monte Carlo code. To this end, a new personalized dosimetric tool was developed ${ }^{3}$ and named OEDIPE, a French acronym which stands for "Tool for Personalized Internal Dose Assessment." OEDIPE has a graphical user interface (GUI), which allows for the creation of patientspecific voxel-based models that can then be associated with a particle transport code, namely, the MCNPX Monte Carlo code. ${ }^{4}$ OEDIPE was designed to permit dose calculations at the voxel level or whole-organ level.

A first validation of OEDIPE has been published previously. We present in this paper a comparison of results obtained with OEDIPE with data published previously by Yoriyaz et al. ${ }^{5}$

In this study, we aimed at comparing results obtained with similar biokinetics in different patient models. We evaluated the dosimetric consequences of defective ${ }^{99 \mathrm{~m}} \mathrm{Tc}$-labeling of hydroxydiphosphonate (HDP) by calculating the increase of the absorbed dose in the liver and spleen, considering these as the only source organs. Two similar nonspecific mathematical models were used, and the results obtained were compared with those calculated using OEDIPE and the Zubal et al. model. ${ }^{6}$

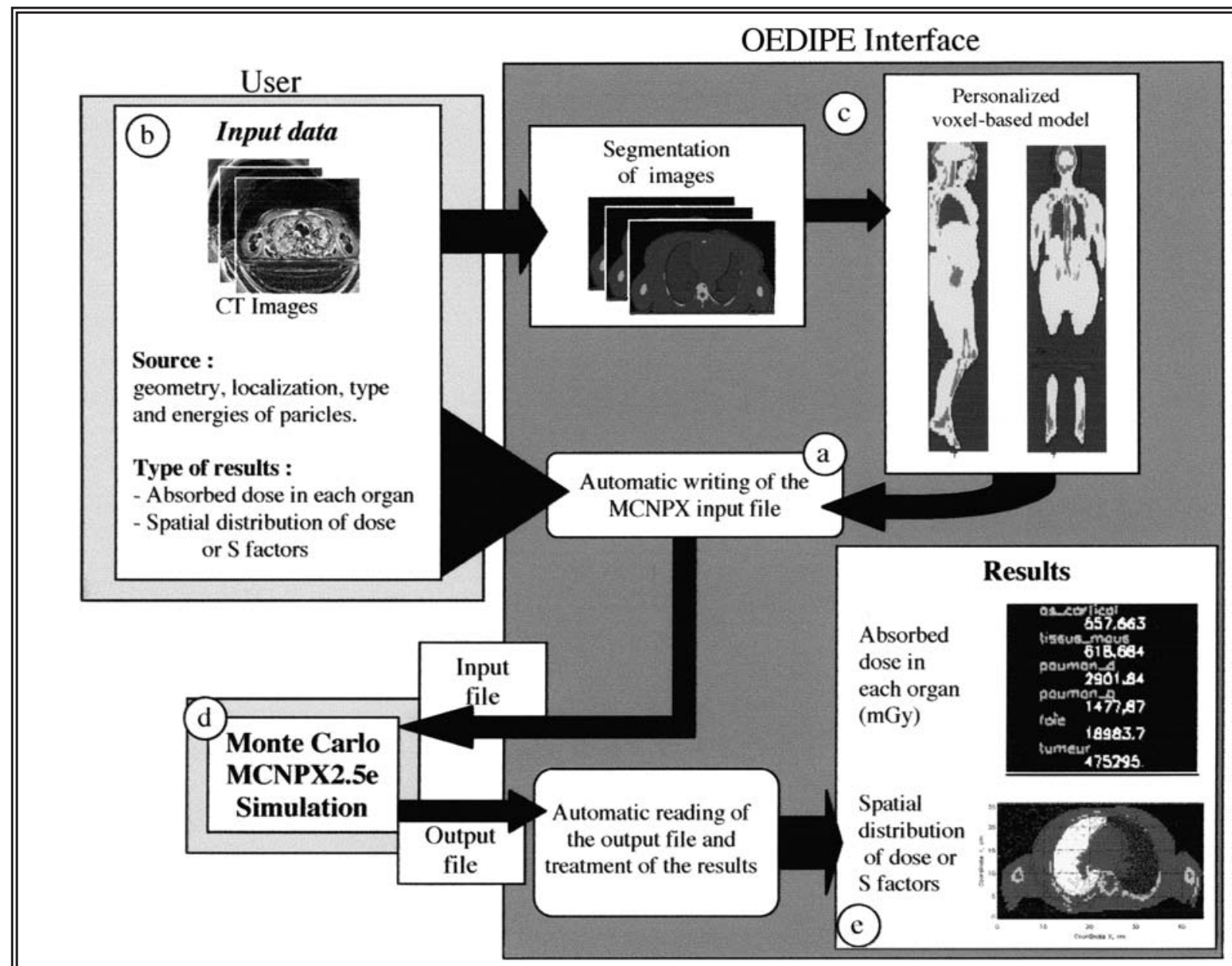

Figure 1. OEDIPE Interface (a-e) 


\begin{tabular}{|c|c|c|c|c|c|c|c|}
\hline \multirow[b]{2}{*}{ Target organ } & \multirow[b]{2}{*}{ Method } & \multicolumn{6}{|c|}{ Source organ } \\
\hline & & Liver & Kidneys & Lungs & Pancreas & Spleen & Adrenals \\
\hline \multirow[t]{2}{*}{ Liver } & $\mathrm{SCMS}^{\mathrm{a}}$ & $4.91 \mathrm{e}-1$ & $6.44 \mathrm{e}-2$ & $1.19 \mathrm{e}-3$ & $2.09 \mathrm{e}-4$ & 0 & $9.87 e-3$ \\
\hline & OEdipe & $4.91 \mathrm{e}-1$ & $3.32 \mathrm{e}-3$ & $1.15 \mathrm{e}-3$ & $2.14 \mathrm{e}-4$ & 0 & $9.73 e-3$ \\
\hline \multirow[t]{2}{*}{ Kidneys } & $\mathrm{SCMS}^{\mathrm{a}}$ & $3.25 \mathrm{e}-3$ & 1.81 & 0 & $1.35 \mathrm{e}-2$ & $6.18 \mathrm{e}-3$ & $7.95 \mathrm{e}-2$ \\
\hline & OEdipe & $3.32 \mathrm{e}-3$ & 1.81 & 0 & $1.33 \mathrm{e}-2$ & $6.19 \mathrm{e}-3$ & $7.89 \mathrm{e}-2$ \\
\hline \multirow[t]{2}{*}{ Lungs } & SCMS $^{\mathrm{a}}$ & $1.27 \mathrm{e}-3$ & 0 & $7.51 \mathrm{e}-1$ & 0 & $4.54 \mathrm{e}-3$ & 0 \\
\hline & OEdipe & $1.30 \mathrm{e}-3$ & 0 & $7.52 \mathrm{e}-1$ & 0 & $4.57 \mathrm{e}-3$ & 0 \\
\hline \multirow[t]{2}{*}{ Pancreas } & $\mathrm{SCMS}^{\mathrm{a}}$ & $2.13 e-4$ & $1.40 \mathrm{e}-2$ & 0 & 16.6 & 0 & $3.71 \mathrm{e}-1$ \\
\hline & OEdipe & $2.13 \mathrm{e}-4$ & $1.33 \mathrm{e}-2$ & 0 & 16.6 & 0 & $3.95 \mathrm{e}-1$ \\
\hline \multirow[t]{2}{*}{ Spleen } & $\mathrm{SCMS}^{\mathrm{a}}$ & 0 & $6.28 \mathrm{e}-3$ & $4.06 e-3$ & 0 & 2.53 & 0 \\
\hline & OEdipe & 0 & $6.20 \mathrm{e}-3$ & $4.07 \mathrm{e}-3$ & $5.40 \mathrm{e}-8$ & 2.53 & 0 \\
\hline \multirow[t]{2}{*}{ Adrenals } & $\mathrm{SCMS}^{\mathrm{a}}$ & $9.11 \mathrm{e}-3$ & $8.05 \mathrm{e}-2$ & 0 & $3.75 \mathrm{e}-1$ & 0 & 171 \\
\hline & OEdipe & $9.65 e-3$ & $8.00 \mathrm{e}-2$ & 0 & $3.71 \mathrm{e}-1$ & 0 & 171 \\
\hline
\end{tabular}

${ }^{\text {aD }}$ ata published by Yoriyaz et al. See ref. 5 .

\section{MATERIALS AND METHODS}

\section{Software Development}

OEDIPE is developed under the PV-Wave ${ }^{\circledR}$ language. It has a friendly graphical user interface (GUI), and generates a MCNPX Monte Carlo code input file (Fig. 1A). The input data are patient CT images, source information, and the type of results required which can be the mean absorbed dose in each organ, the spatial distribution of dose, or $\mathrm{S}$ factors at the voxel level (Fig. 1B). Patient CT images are segmented to obtain a personalized voxel-based model (Fig. 1C). A specific tool allows for CT image segmentation. Four materials are considered (air, lungs, soft tissues, and bones), with each voxel being assigned a tissue index according to a preset Hounsfield scale threshold. Default values range from -1000 to -900 for air, -900 to -400 for lungs, -400 to 200 for soft tissues and at least 200 for bones. These values can be adjusted by the operator.

A manual segmentation is also feasible, and, in that case, a database of 26 tissues or organs from the International Commission on Radiation Units

Table 2. SAF values $\left(\mathrm{kg}^{-1}\right)$ (Photon Energy of $100 \mathrm{keV}$ )

\begin{tabular}{|c|c|c|c|c|c|c|c|}
\hline \multirow[b]{2}{*}{ Target organ } & \multirow[b]{2}{*}{ Method } & \multicolumn{6}{|c|}{ Source organ } \\
\hline & & Liver & Kidneys & Lungs & Pancreas & Spleen & Adrenals \\
\hline \multirow[t]{2}{*}{ Liver } & $\mathrm{SCMS}^{\mathrm{a}}$ & $9.01 \mathrm{e}-2$ & $2.32 \mathrm{e}-2$ & $1.42 \mathrm{e}-2$ & $2.89 \mathrm{e}-2$ & $5.73 e-3$ & $4.35 \mathrm{e}-2$ \\
\hline & OEdipe & $8.67 \mathrm{e}-2$ & $2.19 \mathrm{e}-2$ & $1.29 \mathrm{e}-2$ & $2.79 e-2$ & $5.28 \mathrm{e}-3$ & $4.21 \mathrm{e}-2$ \\
\hline \multirow[t]{2}{*}{ Kidneys } & $\mathrm{SCMS}^{\mathrm{a}}$ & $2.31 \mathrm{e}-2$ & $1.65 \mathrm{e}-1$ & $6.82 \mathrm{e}-3$ & $4.36 e-2$ & $3.65 e-2$ & $7.65 e-2$ \\
\hline & OEdipe & $2.16 \mathrm{e}-2$ & $1.62 \mathrm{e}-1$ & $6.16 \mathrm{e}-3$ & $4.23 \mathrm{e}-2$ & $3.43 \mathrm{e}-2$ & $7.48 \mathrm{e}-2$ \\
\hline \multirow[t]{2}{*}{ Lungs } & SCMS $^{\mathrm{a}}$ & $1.42 \mathrm{e}-2$ & $6.81 \mathrm{e}-3$ & $5.02 \mathrm{e}-2$ & $1.14 \mathrm{e}-2$ & $1.70 \mathrm{e}-2$ & $1.27 \mathrm{e}-2$ \\
\hline & OEdipe & $1.30 \mathrm{e}-2$ & $6.22 \mathrm{e}-3$ & $4.88 \mathrm{e}-2$ & $1.07 \mathrm{e}-2$ & $1.56 \mathrm{e}-2$ & $1.19 \mathrm{e}-2$ \\
\hline \multirow[t]{2}{*}{ Pancreas } & $\mathrm{SCMS}^{\mathrm{a}}$ & $2.88 \mathrm{e}-2$ & $4.35 \mathrm{e}-2$ & $1.12 \mathrm{e}-2$ & $8.20 \mathrm{e}-1$ & $3.54 \mathrm{e}-2$ & $1.60 \mathrm{e}-1$ \\
\hline & OEdipe & $2.85 \mathrm{e}-2$ & $4.30 \mathrm{e}-2$ & $1.10 \mathrm{e}-2$ & $8.15 \mathrm{e}-1$ & $3.34 \mathrm{e}-2$ & $1.57 \mathrm{e}-1$ \\
\hline \multirow[t]{2}{*}{ Spleen } & $\mathrm{SCMS}^{\mathrm{a}}$ & $5.75 \mathrm{e}-3$ & $3.62 \mathrm{e}-2$ & $1.67 \mathrm{e}-2$ & $3.51 \mathrm{e}-2$ & $2.59 \mathrm{e}-1$ & $2.47 \mathrm{e}-2$ \\
\hline & OEdipe & $5.25 \mathrm{e}-3$ & $3.39 \mathrm{e}-2$ & $1.54 \mathrm{e}-2$ & $3.28 \mathrm{e}-2$ & $2.51 \mathrm{e}-1$ & $2.34 \mathrm{e}-2$ \\
\hline \multirow[t]{2}{*}{ Adrenals } & SCMS $^{\mathrm{a}}$ & $4.31 \mathrm{e}-2$ & $7.55 \mathrm{e}-2$ & $1.30 \mathrm{e}-2$ & $1.63 \mathrm{e}-1$ & $2.33 \mathrm{e}-2$ & 3.34 \\
\hline & OEdipe & $4.05 \mathrm{e}-2$ & $7.57 e-2$ & $1.21 \mathrm{e}-2$ & $1.59 \mathrm{e}-1$ & $2.39 \mathrm{e}-2$ & 3.31 \\
\hline
\end{tabular}

aData published by Yoriyaz et al. See ref. 5. 


\begin{tabular}{|c|c|c|c|c|c|c|c|}
\hline \multirow[b]{2}{*}{ Target organ } & \multirow[b]{2}{*}{ Method } & \multicolumn{6}{|c|}{ Source organ } \\
\hline & & Liver & Kidneys & Lungs & Pancreas & Spleen & Adrenals \\
\hline \multirow[t]{2}{*}{ Liver } & SCMS $^{\mathrm{a}}$ & $7.58 \mathrm{e}-2$ & $1.74 \mathrm{e}-2$ & $1.07 \mathrm{e}-2$ & $2.10 \mathrm{e}-2$ & $4.82 \mathrm{e}-3$ & $3.22 \mathrm{e}-2$ \\
\hline & OEdipe & $7.54 \mathrm{e}-2$ & $1.73 \mathrm{e}-2$ & $1.06 \mathrm{e}-2$ & $2.08 \mathrm{e}-2$ & $4.69 \mathrm{e}-3$ & $3.19 \mathrm{e}-2$ \\
\hline \multirow[t]{2}{*}{ Kidneys } & SCMS $^{\mathrm{a}}$ & $1.76 \mathrm{e}-2$ & $1.51 \mathrm{e}-1$ & $5.49 \mathrm{e}-3$ & $3.34 \mathrm{e}-2$ & $2.82 \mathrm{e}-2$ & $6.34 \mathrm{e}-2$ \\
\hline & OEdipe & $1.72 \mathrm{e}-2$ & $1.51 \mathrm{e}-1$ & $5.45 \mathrm{e}-3$ & $3.31 \mathrm{e}-2$ & $2.78 \mathrm{e}-2$ & $6.33 \mathrm{e}-2$ \\
\hline \multirow[t]{2}{*}{ Lungs } & SCMS $^{\mathrm{a}}$ & $1.07 \mathrm{e}-2$ & $5.53 \mathrm{e}-3$ & $4.25 \mathrm{e}-2$ & $8.32 \mathrm{e}-3$ & $1.29 \mathrm{e}-2$ & $9.35 e-3$ \\
\hline & OEdipe & $1.04 \mathrm{e}-2$ & $5.48 \mathrm{e}-3$ & $4.28 \mathrm{e}-2$ & $8.22 \mathrm{e}-3$ & $1.27 \mathrm{e}-2$ & $9.30 \mathrm{e}-3$ \\
\hline \multirow[t]{2}{*}{ Pancreas } & SCMS $^{\mathrm{a}}$ & $2.10 \mathrm{e}-2$ & $3.26 \mathrm{e}-2$ & $8.18 \mathrm{e}-3$ & $7.97 \mathrm{e}-1$ & $2.41 \mathrm{e}-2$ & $1.37 \mathrm{e}-1$ \\
\hline & OEdipe & $2.16 \mathrm{e}-2$ & $3.31 \mathrm{e}-2$ & $8.64 \mathrm{e}-3$ & $7.95 \mathrm{e}-1$ & $2.42 \mathrm{e}-2$ & $1.36 \mathrm{e}-1$ \\
\hline \multirow[t]{2}{*}{ Spleen } & SCMS $^{\mathrm{a}}$ & $4.82 \mathrm{e}-3$ & $2.80 \mathrm{e}-2$ & $1.28 \mathrm{e}-2$ & $2.46 \mathrm{e}-2$ & $2.37 \mathrm{e}-1$ & $1.85 \mathrm{e}-2$ \\
\hline & OEdipe & $4.79 \mathrm{e}-3$ & $2.78 \mathrm{e}-2$ & $1.25 \mathrm{e}-2$ & $2.42 \mathrm{e}-2$ & $2.36 \mathrm{e}-1$ & $1.82 \mathrm{e}-2$ \\
\hline \multirow[t]{2}{*}{ Adrenals } & $\mathrm{SCMS}^{\mathrm{a}}$ & $3.31 \mathrm{e}-2$ & $6.22 \mathrm{e}-2$ & $9.45 \mathrm{e}-3$ & $1.38 \mathrm{e}-1$ & $1.85 \mathrm{e}-2$ & 3.20 \\
\hline & OEdipe & $3.13 \mathrm{e}-2$ & $6.61 \mathrm{e}-2$ & $9.93 e-3$ & $1.36 \mathrm{e}-1$ & $1.74 \mathrm{e}-2$ & 3.22 \\
\hline
\end{tabular}

and Measurements (ICRU) report no. $44^{7}$ is available. Source data, such as localization of the VOI and cumulated activities, are assessed from single photon emission computed tomography (SPECT) images and the source may be specified either as point sources or as homogeneously distributed sources in any number of specified organs. A total of 246 radionuclides $^{8}$ are available for calculations.

Simulation is carried out with the MCNPX Monte Carlo code, version 2.5e (Fig. 1D). OEDIPE can compute either the absorbed dose in each organ (in a few minutes), or the absorbed dose in each voxel of the model (in a few hours or more). This would represent the spatial-dose distribution at a tissue level, and this can be superimposed onto the anatomical data of the model as two-dimensional isodose curves (Fig. 1E).

\section{MCNPX Monte Carlo Code}

MCNPX, a general Monte Carlo N-Particle transport code, represents a major extension of the MCNP code, ${ }^{9}$ allowing for the ability to track all types of particles. This code enables a relatively easy specification of complex geometries and sources. The default cut-off energies are $1 \mathrm{keV}$ for photons and electrons. For photons, coherent scattering is considered. Secondary electron transport is considered with the "Thick-TargetBremsstrahlung model" (TTB) that entails immediately annihilating the secondary electrons and tracking the bremsstrahlung photons locally produced. For the electron transport, MCNPX uses the "condensed history" Monte Carlo method from ITS 3.0.

Although Monte Carlo calculations can be very time-consuming, recent developments of MCNPX involving the "repeated structure" format allows simulations to be performed with more reasonable computation times (CPU). Preliminary studies showed that using MCNPX2.5e with the repeated structure format ${ }^{10}$ reduced the computation time by a factor equal to or higher than 100, when compared with MCNPX version 2.4 (data not shown).

\section{OEDIPE Validation}

We previously reported the validation of OEDIPE against an EGS4-based Monte Carlo code in a dosimetric study performed in the

Table 4. S values (mGy/MBq.s) Electron Energy of $0.935 \mathrm{MeV}$

\begin{tabular}{lcccc}
\hline \multirow{2}{*}{ Target organ } & & \multicolumn{3}{c}{ Source organ } \\
\cline { 3 - 5 } & Method & Liver & Kidneys & Lungs \\
\hline \multirow{2}{*}{ Liver } & SCMS $^{\mathrm{a}}$ & $7.35 \mathrm{e}-5$ & $4.42 \mathrm{e}-7$ & $1.76 \mathrm{e}-7$ \\
\multirow{3}{*}{ Kidneys } & OEdipe & $7.36 \mathrm{e}-5$ & $4.52 \mathrm{e}-7$ & $1.72 \mathrm{e}-7$ \\
& SCMS $^{\mathrm{a}}$ & $4.65 \mathrm{e}-7$ & $2.72 \mathrm{e}-4$ & $3.17 \mathrm{e}-9$ \\
Lungs & OEdipe $^{\mathrm{y}}$ & $4.55 \mathrm{e}-7$ & $2.71 \mathrm{e}-4$ & $2.52 \mathrm{e}-9$ \\
& SCMS & $1.73 \mathrm{e}-7$ & 0 & $1.12 \mathrm{e}-4$ \\
& OEdipe & $1.74 \mathrm{e}-7$ & $2.52 \mathrm{e}-9$ & $1.12 \mathrm{e}-4$ \\
& & & &
\end{tabular}

aData published by Yoriyaz et al. See ref. 5 . 
course of treatment of medullary thyroid cancer. Results obtained for the same geometric conditions and similar biokinetics were very similar. ${ }^{11}$

In this study, we show a comparison with data published by Yoriyaz et al..$^{5}$ for the Zubal et al. model $^{6}$ and the MCNP4 $\mathrm{b}^{9}$ code (see Tables 1-4). The physic of the two codes, MCNP4b and MCNPX2.5e, is similar. The geometry used was the Zubal et al. model, considering three distinct tissue types: soft tissue, lung, and bone, with densities of $1.04,0.296$, and $1.40 \mathrm{~g} / \mathrm{cm}^{3}$, respectively. For Yoriyaz et al., calculations were carried out through the use of the SCMS software. Specific absorbed fractions (SAFs) were calculated for photons of $0.01,0.1$, and $1 \mathrm{MeV}$, and $\mathrm{S}$ values for electrons of $0.935 \mathrm{MeV}$, in various target organs. Emissions were assumed to be distributed uniformly in the various source organs.

In order to keep statistical uncertainties below $5 \%$, we simulated 1-10 million emissions for 0.1 and $1 \mathrm{MeV}$ photons, and 100 million emissions for $10 \mathrm{keV}$ photons. Statistical uncertainties are not given in the published data, but 2-10 million photons were simulated. ${ }^{6}$ Similarly, 1-5 million electrons were simulated to keep statistical uncertainties below $5 \%$.

\section{Biological Data}

Defective labeling conditions were reproduced experimentally by the Biophysics Laboratory of the Faculty of Medicine Xavier Bichat (Paris, France). Activities of ${ }^{99 \mathrm{~m}} \mathrm{Tc}-\mathrm{HDP}$ fixed in the liver and spleen were measured experimentally in the rat ${ }^{12}$ for the normal and defective case at various times, and percentages of injected activity were calculated. For the sake of this study, these are assumed to be identical for humans. As expected, we observed a significant increase of liver and spleen uptake in the defective case (Table 5). Knowing the activity of ${ }^{99 \mathrm{~m}} \mathrm{Tc}-\mathrm{HDP}$ injected in humans, we calculated the activity expressed in $\mathrm{Bq}$ at various times in the liver and spleen (Table 6).

Table 5. Percent Injected Activities in Liver and Spleen for the Normal and Defective Case at Various Times

\begin{tabular}{llrrc}
\hline Case & Source & $5 \mathrm{~min}$ & $30 \mathrm{~min}$ & $120 \mathrm{~min}$ \\
\hline Defective & Liver & $49.6 \%$ & $38.8 \%$ & $33.0 \%$ \\
Defective & Spleen & $2.8 \%$ & $1.5 \%$ & $0.6 \%$ \\
Normal & Liver & $3.9 \%$ & $1.8 \%$ & - \\
Normal & Spleen & $0.1 \%$ & $0.3 \%$ & - \\
\hline
\end{tabular}

Table 6. Activities $(\mathrm{Bq})$ in Liver and Spleen for the Normal and Defective Case at Various Times

\begin{tabular}{llccc}
\hline Case & Source & $5 \mathrm{~min}$ & $30 \mathrm{~min}$ & $120 \mathrm{~min}$ \\
\hline Defective & Liver & $3.68 \mathrm{e}+8$ & $2.75 \mathrm{e}+8$ & $1.95 \mathrm{e}+8$ \\
Defective & Spleen & $2.09 \mathrm{e}+7$ & $1.11 \mathrm{e}+7$ & $3.75 \mathrm{e}+6$ \\
Normal & Liver & $2.91 \mathrm{e}+7$ & $1.27 \mathrm{e}+7$ & - \\
Normal & Spleen & $1.14 \mathrm{e}+6$ & $2.41 \mathrm{e}+6$ & - \\
\hline
\end{tabular}

\section{Absorbed-Dose Calculation}

Using the MIRD formalism, ${ }^{1}$ the dose rate (Gy/s) in a target organ $m$ from the liver and spleen source organs is calculated according to:

$\bar{D}=A_{\text {Liver }} \times S_{m \leftarrow \text { Liver }}+A_{\text {Spleen }} \times S_{m \leftarrow \text { Spleen }}$

where $A$ is the activity expressed in $\mathrm{Bq}$ and the $S$ factors are expressed in Gy per disintegrationor per Bq.s.

These $\mathrm{S}$ factors were obtained using three methods:

- The SEECAL software developed by Cristy and Eckerman, ${ }^{13}$ which calculates $S$ factors in the Reference Man, as described in ICRP 23. ${ }^{14}$

- The MIRD Pamphlet no. $11,{ }^{15}$ which gives tables of $S$ values for the adult male described in the MIRD Pamphlet no. 5, revised. ${ }^{16}$

- Calculation of $S$ factors for the Zubal et al. model by using OEDIPE and MCNPX.

Using OEDIPE, two simulations were performed to obtain $\mathrm{S}$ factors in 21 target organs for the liver and spleen as source organs. The source distribution was presumed to be homogeneous in those two latter organs, and emission data were taken from the MIRD decay data compendium. ${ }^{8}$ In order to have an uncertainty below $10 \%$ for each target organ, 5 million histories (for both photons and electrons) were followed for each source organ. Computational (CPU) times were approximately 1.59 and 2.75 hours for liver and spleen as source organs, respectively (using a power Mac G5 $2 \times 2 \mathrm{GHz}$ ).

\section{Models}

Three models (Reference Man of ICRP 23, Adult Male model of MIRD Pamphlet no. 5-revised, and the Zubal et al. model) were used for this study. The Zubal et al. model was chosen because the organ geometry, mass, and position are sim- 
Table 7. Organs Masses (kg) of the Zubal et al. Model, the Reference Man Described by ICRP 23 and the Adult Male Described in MIRD Pamphlet No. 5-Revised

\begin{tabular}{|c|c|c|c|}
\hline & $\begin{array}{c}\text { Zubal et al. model } \\
\text { (with arms and legs) }\end{array}$ & $\begin{array}{l}\text { Reference man } \\
\quad \text { ICRP } 23\end{array}$ & $\begin{array}{l}\text { Adult male } \\
\text { MIRD } 5 \text { revised }\end{array}$ \\
\hline Organs/tissues & Mass (kg) & Mass (kg) & Mass (kg) \\
\hline Adrenals & 0.003 & 0.014 & 0.016 \\
\hline UB_Wall & 0.154 & 0.045 & 0.045 \\
\hline Bone & 11.097 & 7.000 & 7.474 \\
\hline Brain & 0.238 & 1.400 & \\
\hline St_Wall & 0.084 & 0.150 & 0.150 \\
\hline SI_Wall & 1.296 & 0.640 & 0.644 \\
\hline ULI_Wall + LLI_Wall & 0.896 & 0.370 & 0.369 \\
\hline Kidneys & 0.373 & 0.310 & 0.284 \\
\hline Liver & 1.448 & 1.800 & 1.809 \\
\hline $\mathrm{ET}$ & 0.0004 & 0.015 & \\
\hline Lung Tissue & 0.756 & 1.000 & 0.999 \\
\hline Muscle & 36.404 & 28.000 & 28.000 \\
\hline Pancreas & 0.0384 & 0.100 & 0.060 \\
\hline Red Marrow & 1.439 & 1.500 & 1.500 \\
\hline Skin & 5.218 & 2.600 & 2.833 \\
\hline Spleen & 0.275 & 0.180 & 0.174 \\
\hline Testes & 0.0725 & 0.035 & 0.038 \\
\hline Thymus & 0.0315 & 0.020 & \\
\hline Thyroid & 0.0051 & 0.020 & 0.020 \\
\hline GB_Wall & 0.0161 & 0.010 & \\
\hline Ht_Wall & 0.458 & 0.330 & \\
\hline
\end{tabular}

MIRD, Medical Internal Radiation Dose

ilar to those encountered in real patients. Table 7 shows the masses of some target organs for the three models used. The organ masses of the two mathematical models are very similar but can differ substantially from those of the Zubal et al. model.

\section{RESULTS}

\section{OEDIPE Validation}

Tables 1-3 present specific absorbed fractions (SAFs) $\left(\mathrm{kg}^{-1}\right)$ for photons of $0.01,0.1$, and 1 $\mathrm{MeV}$, respectively. For $10 \mathrm{keV}$ photons, varia- tions between published data and our calculations are below $6 \%$, except for $\mathrm{SAF}_{\text {(Liver } \leftarrow \text { Kidneys) }}$. No explanation could be given for that abnormality. For 0.1 and $1 \mathrm{MeV}$ photons, variations lower than $10 \%$ and $7 \%$, respectively, were found.

Table 4 presents $\mathrm{S}$ values (mGy/MBq.s) for electrons of $0.935 \mathrm{MeV}$. Variations are below $3 \%$, except for very small values, $\mathrm{S}_{\text {(Lungs } \leftarrow \text { Kidneys) }}$ and $\mathrm{S}_{\text {(Kidneys } \leftarrow \text { Lungs) }}$.

\section{Defective ${ }^{99 m}$ Tc HDP Labeling}

Ratios of absorbed dose in liver and spleen obtained from the three methods are very similar (Table 8). Defective ${ }^{99 \mathrm{~m}}$ Tc-HDP administration

Table 8. The Ratio of Absorbed Dose Between Defective and Normal Cases in Liver and Spleen Obtained from Three Different Methods

\begin{tabular}{|c|c|c|c|}
\hline & SEECAL + Reference man & MIRDI1 + Adult male & $O E D I P E+Z u b a l$ \\
\hline $\mathrm{H}_{\text {liver }}(50) \mathrm{D} / \mathrm{H}_{\text {liver }}(50) \mathrm{N}$ & 20.02 & 20.02 & 19.98 \\
\hline $\mathrm{H}_{\text {spleen }}(50) \mathrm{D} / \mathrm{H}_{\text {spleen }}(50) \mathrm{N}$ & 3.79 & 3.77 & 3.86 \\
\hline
\end{tabular}


Table 9. Mean Absorbed Dose (mGy) for the Defective Case in Liver, Spleen, and Kidneys, Obtained from Three Methods

\begin{tabular}{lccc}
\hline & SEECAL & MIRD 11 & OEDIPE \\
\hline Liver & 31 & 31 & 36 \\
Spleen & 7.1 & 7.3 & 4.9 \\
Kidneys & 2.8 & 2.8 & 5 \\
\hline
\end{tabular}

results in an increase of the absorbed dose in the liver and spleen by a factor of approximately 20 and 4, respectively, when compared with correctly labeled HDP administration (taking into account only irradiation from those two organs).

However, the mean absorbed doses obtained from the three methods were sometimes quite different, particularly for OEDIPE calculations with the Zubal et al. model. Table 9 shows the mean absorbed doses in the liver, spleen, and kidneys obtained from the three methods in the defective case. Table 10 presents variations between these absorbed doses and target organ masses, depending on the models used. For example, the variation between the mean absorbed doses obtained from MIRD 11 and OEDIPE in kidneys is approximately $78 \%$. This variation is probably due partly to the difference in masses of approximately $31 \%$ for kidneys and approximately $20 \%$ for liver between the two models used. Moreover, we noticed a difference in the geometry of kidneys and liver between the two models, the Zubal et al. model being more realistic (Fig. 2). Another factor explaining this variation is the difference in positioning of kidneys compared to the liver. ${ }^{5}$ The adult male model defined by the MIRD Pamphlet no. 5 does not present a superposition of the right kidney on the liver, in contrast to the Zubal et al. model (Fig. 2).

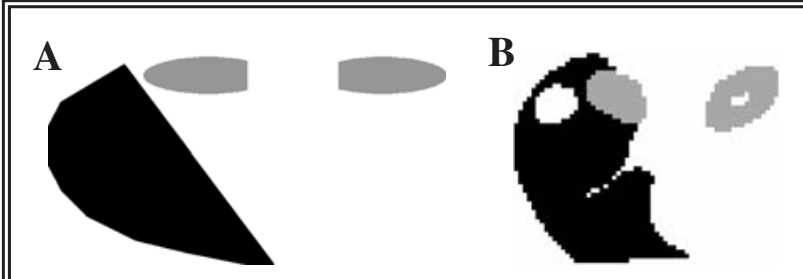

Figure 2. Kidneys (grey) and liver (black) as represented for the adult male model (A) and the Zubal model (B).

\section{DISCUSSION}

The ever-increasing computing power allows for Monte Carlo dosimetric calculations to be performed at the patient level (i.e., by taking into account "real patient" characteristics, at least in terms of propagation media). Validation of such calculations is not a trivial issue.

There are several causes to the variations observed when comparing results available in the literature.

Results can be obtained by using different codes or different models (including mathematical or voxel-based models). Then, for a given code, the calculation schemes can be different (organ or voxel-based calculations).

Our results (obtained by a limited data set) show that there were no significant differences between our results and those obtained by Yoryiaz et al. with the same (Zubal et al.) model and different versions of MCNP (with the exception of an abnormal discrepancy observed for a single target-source combination at $10 \mathrm{keV}$ ). Furthermore, previous results indicated very little differences when using the same geometrical model and different Monte Carlo code (MCNPX and EGS4). However, a major source of variation can be introduced when using mathematical models, as compared to voxel-based models, or at least when organ geometries differ markedly.

\begin{tabular}{|c|c|c|c|c|c|c|}
\hline & \multicolumn{2}{|c|}{ SEECAL/MIRD 11} & \multicolumn{2}{|c|}{ SEECAL/OEDIPE } & \multicolumn{2}{|c|}{ MIRD 11/OEDIPE } \\
\hline & Dose \% & Mass \% & Dose \% & Mass \% & Dose \% & Mass \% \\
\hline Liver & 0.0 & 0.5 & 16.1 & 19.6 & 16.1 & 20.0 \\
\hline Spleen & 2.8 & 3.3 & 31.0 & 53.0 & 32.9 & 58.3 \\
\hline Kidneys & 0.0 & 8.4 & 78.6 & 20.4 & 78.6 & 31.4 \\
\hline
\end{tabular}


The dosimetric study presented in this paper was performed using two standard methods and a specific Monte Carlo calculation using OEDIPE and the Zubal et al. voxel-based model. Factors of increase of the absorbed dose in the liver and spleen obtained from these three methods are very similar: Defective ${ }^{99 \mathrm{~m}} \mathrm{Tc}-\mathrm{HDP}$ administration results in an increase of the absorbed dose in the liver and spleen of approximately 20 and 4, respectively, when compared with correct HDP administration. However, $S$ values obtained with the three methods present significant variations: Dosimetric results obtained with the SEECAL software and those available from the MIRD Pamphlet no. 11 are close but differ from those obtained with OEDIPE and the Zubal et al. model. Indeed, the mass, shape, and position of target and source organs do differ a lot between ICRP 23 Reference Man and the MIRD Pamphlet no. 5 Adult Male on one hand, and the Zubal et al. voxel model one the other hand, regardless of the S-value-calculation scheme. The dose conversion factors ( $\mathrm{S}$ values) can vary significantly, according to the geometric model used. This may be of less importance in cases where approximate dose estimates are sufficient (i.e., for radiation safety purposes in diagnostics procedures where doses are low). However, when high doses are delivered (for example, for therapeutic applications) and a great level of accuracy is sought, patient-based dosimetry should be carried out.

\section{CONCLUSIONS}

OEDIPE enables a full 3D Monte Carlo dosimetry study to be performed. Patient images (CT and SPECT) are input and processed through a friendly GUI. One important feature is the possibility to first segment the patient data and to carry out organ dosimetry, which decreases calculation times dramatically (from some days down to some hours on commonly available workstations, thus allowing its implementation in a clinical context). The dosimetric calculation is carried out through the use of a well-established Monte Carlo code. The use of OEDIPE for dosimetry in targeted radiotherapy clinical trials is planned following further validation that will use thermoluminescent dosimeters ${ }^{17}$ in experimental anthropomorphic phantoms.

\section{ACKNOWLEDGEMENT}

The authors wish to thank Dr. Glenn Flux for checking the manuscript.

\section{REFERENCES}

1. Loevinger R, Budinger T, Watson E. MIRD primer for absorbed dose calculations. New York: Society of Nuclear Medicine, 1988.

2. Bardiès M, Pihet P. Dosimetry and microdosimetry of targeted radiotherapy. Curr Pharmaceut Des 2000; $6: 1469$.

3. Aubineau-Lanièce I, De Carlan L, Clairand I, et al. New tools based on voxel phantom for both internal and external exposures dose assessment. Radiat Prot Dosim 2004; in press.

4. Hughes HG, Prael RE, Little RC. MCNPX the LAHET/MCNP code merger. XTM-RN (U) 1997;97.

5. Yoriyaz H, Dos Santos A. Absorbed fractions in a voxel-based phantom calculated with the MCNP-4B code. Med Phys 2000;27(7):1555.

6. Zubal IG, Harrell CR, Smith EO, et al. Computerized 3-dimensional segmented human anatomy. Med Phys 1994;21:299.

7. International Commission on Radiation Units and Measurements. Tissue substitutes in radiation dosimetry and measurement. ICRU report no. 44. Maryland: Bethesda, 1989.

8. Eckerman KF, Weestfall RJ, Rymann JC et al. Availability of nuclear decay data in electronic form, including beta spectra not previously published. Health Phys 1994;67:338.

9. Briesmeister JF. MCNP ${ }^{\mathrm{TM}}-\mathrm{A}$ general Monte Carlo $\mathrm{N}$-particle transport code, version 4B. Los Alamos, New Mexico: Los Alamos National Laboratory Report, LA12625-M, 1997.

10. Hendricks JS. MCNPX, Version 2.5e. 2004;LA-UR-040569.

11. Chiavassa S, Lemosquet A, Aubineau-Lanièce I, et al. Dosimetric comparison of Monte Carlo codes (EGS4, MCNP, MCNPX) considering external and internal exposures of the Zubal phantom to electron and photon sources. Radiat Prot Dosim 2004; in press.

12. Gaylord King A, Christy B, Hupf HB, et al. A chemical analysis of average chain length and relationship to bone deposition in rats. J Nucl Med 1973;14(9):695.

13. Cristy M, Eckerman KF. SEECAL: Program to calculate age-dependent specific effective energies. 1993; ORNL/TM-12351.

14. Snyder WS, Cook MJ, Nasset ES, et al. ICRP Report of the Task Group on Reference Man. Publication no. 23. Oxford: Pergamon Press, 1975.

15. Snyder WS, Ford MR, Warner GG, et al. "S," absorbed dose per unit cumulative activity for selected radionuclides and organs. MIRD Pamphlet no. 11. New York: The Society of Nuclear Medicine, 1975.

16. Snyder WS, Ford MR, Warner GG. Estimates of absorbed fractions for monoenergetic photon sources uniformly distributed in various organs of a heterogeneous phantom. MIRD Pamphlet no. 5, revised. New York: The Society of Nuclear Medicine, 1978.

17. Jarnet D, Denizot B, Hindré F, et al. New thermoluminescent dosimeters (TLD): Optimization and characterization of TLD threads sterilizable by autoclave. Phys Med Biol 2004;49:1803. 